\title{
Inhibitory Effects of Chloroform Extracts Derived from Corbicula fluminea on the Release of Pro-inflammatory Cytokines
}

\author{
Ching-Min Lin, ${ }^{\dagger}+$ Yu-Ling Lin, ${ }^{\dagger \neq}{ }^{\ddagger} \mathrm{Nu}-\mathrm{Man}$ Tsai, ${ }^{\S}$ Hsin-Yi Wu, ${ }^{\ddagger}$ Shu-Yi Ho, ${ }^{\|}$Chia-Hung Chen, ${ }^{\ddagger}$
} Yen-Ku Liu, ${ }^{\ddagger}$ Yi-Han Chiu, ${ }^{\prime}$ Li-Ping Ho, ${ }^{\|}$Ru-Ping Lee, ${ }^{*, \perp, \#}$ and Kuang-Wen Liao*, ${ }^{*, \neq, \|}$

${ }^{\ddagger}$ Institute of Molecular Medicine and Bioengineering, and "Department of Biological Science and Technology, National Chiao Tung University, Hsinchu 30068, Taiwan, Republic of China

${ }^{\S}$ School of Medical and Laboratory Biotechnology, Chung Shan Medical University, Taichung 40201, Taiwan, Republic of China

\# Department of Nursing, Tzu Chi University, Hualien 97004, Taiwan, Republic of China

\section{Supporting Information}

ABSTRACT: Corbicula fluminea, the primary freshwater bivalve cultivated in Taiwan, was formerly used as a remedy for hepatitis. Recent reports indicate that $C$. fluminea has many bioactivities, but it remains unknown whether $C$. fluminea affects inflammation. This study explored the anti-inflammatory activity of $C$. fluminea. C. fluminea was first treated with chloroform to obtain clam chloroform extracts (CCEs). On the basis of the assay for the release of pro-inflammatory cytokines in vitro and in vivo, the results show that the CCEs significantly lowered the release of lipopolysaccharide (LPS)-induced pro-inflammatory cytokines. Additionally, the CCEs reduced LPS-induced organ damage. Real-time polymerase chain reaction analysis suggested that CCEs inhibit the LPS-induced mRNA expression of interleukin- $1 \beta$ and tumor necrosis factor- $\alpha$. Western blot analysis indicated that the CCEs increased expression of $\mathrm{I} \kappa \mathrm{B}$ and attenuated the phosphorylation of $\mathrm{I} \kappa \mathrm{B}$. Gas chromatography-mass spectrometry suggests that phytosterols and fatty acids are responsible for the anti-inflammatory properties of CCEs. Taken together, CCEs have the potential to be developed as an anti-inflammatory functional food.

KEYWORDS: Freshwater clam, IL-1 $\beta$, inflammation, I $\kappa B-\alpha$, TNF- $\alpha$

\section{INTRODUCTION}

Inflammation is a protective response against infection. However, many chronic diseases, including cancer, hypertension, atherosclerosis, and arthritis are associated with persistent inflammation. ${ }^{1}$ Currently, anti-inflammatories of natural origin are prescribed for the treatment of inflammatory disorders. $^{2}$ In the search for anti-inflammatory drugs, proinflammatory cytokines are good indicators of efficacy.

The release of tumor necrosis factor- $\alpha$ (TNF- $\alpha$ ) by macrophages results in higher vascular permeability, which leads to granulocyte infiltration and initiates the innate immune response. Elevated TNF- $\alpha$ synthesis has also been associated with the development of diabetes, septic shock, tumorigenesis, rheumatoid arthritis, and inflammatory bowel disease. Currently, several protein-based drugs, including etanercept, infliximab, and adalimumab, are available for the clinical inhibition of TNF- $\alpha$ activity. ${ }^{2}$ In addition, excessive production of interleukin- $1 \beta$ (IL-1 $\beta$ ) induces fever and is thought to be a key mediator of inflammation. ${ }^{3}$ Interleukin-6 (IL-6) is an integral cytokine mediator of acute inflammation in response to injury or infection. During acute inflammation, IL-6 might favor the resolution of neutrophilic infiltrates and the initiation of the immune response. ${ }^{4}$ Therefore, assessment of possible antiinflammatory substance(s) may be accomplished by monitoring the expression of pro-inflammatory cytokines, such as TNF- $\alpha$, IL- $1 \beta$, and IL-6.

Corbicula fluminea is a bivalve that is native to southeast Asia. In Taiwanese traditional medicine, this freshwater clam is used for its therapeutic effects on the liver. Patients with liver disease or chronic hepatitis are encouraged to consume soup made with this clam. Recently, the efficacy of this traditional remedy has been confirmed. Reports show that hot water extracts from the freshwater clam have hepatoprotective effects in rats with liver injuries induced by carbon tetrachloride. ${ }^{5}$ Such extracts have also been shown to significantly reduce alcoholic liver injury in pigs. ${ }^{6}$ In addition to its hepatoprotective activity, $C$. fluminea has also been shown to have other bioactivities, including the following. (1) Antihypertensive effect: the PX5 (Val-Lys-Pro and Val-Lys-Lys peptides) derived from the digestion of this clam by Protamex can inhibit the activity of angiotensin-I-converting enzyme to prevent the production of angiotensin II. $^{7}$ (2) Anticancer effects: the substance(s) extracted from the freshwater clam with methanol and then partitioned with ethyl acetate can induce apoptosis of human leukemia HL-60 cells by upregulation of Bax and Bad and downregulation of Bcl-2 and Bcl- $\mathrm{X}_{\mathrm{L}}{ }^{8}$ (3) Hypocholesterolemic and hypolipidemic effects: hot water extracts may ameliorate xenobiotic-induced hypercholesterolemia and hepatosteatosis by changing the gene expression of apo A-I, malic enzyme (ME), and glucose-6-phosphate dehydrogenase (G6PD). ${ }^{9}$ Recent reports show that post-treatment freshwater clam (C. fluminea) extract (FCE) suppresses the release of proinflammatory TNF- $\alpha$ after hemorrhagic shock (HS) and

Received: December 13, 2011

Revised: $\quad$ March 30, 2012

Accepted: April 4, 2012

Published: April 4, 2012 
decreases the levels of markers of liver injury associated with HS in rats. ${ }^{10}$

In this study, the relationships between $C$. fluminea and inflammation were evaluated. The results clearly indicate that clam chloroform extracts (CCEs) lower the production of lipopolysaccharide (LPS)-induced pro-inflammatory cytokines, including TNF- $\alpha$, IL- $1 \beta$, and IL-6, but that clam hot water extracts (CWEs) do not. According to the results of pathology and biophysics experiments, the CCEs did not harm living tissues and reduced LPS-induced tissue damage. These protective activities may result from the anti-inflammatory capacity of the CCEs, which stimulate the overexpression of $\mathrm{I} \kappa \mathrm{B}$ to reduce the expression of pro-inflammatory cytokine genes, a mechanism in which certain phytosterols and fatty acids may play an important role.

\section{MATERIALS AND METHODS}

Preparation of Clam Crude Extracts. Clam powders were provided by Mike Biological Technologies Company (Taipei, Taiwan, Republic of China). Whole freshwater clam powder was added to chloroform at a $1: 10(\mathrm{w} / \mathrm{w})$ ratio. After resting for $12 \mathrm{~h}$ at room temperature, the mixture was filtered through No. 1 filter paper (Toyo Roshi Kaisha, Tokyo, Japan). The insoluble material was removed by centrifugation at $4500 \mathrm{~g}$ for $20 \mathrm{~min}$. The supernatant was filtered through No. 1 filter paper again, and the filtrate was dried in a rotation evaporator under vacuum. It was then dissolved in dimethyl sulfoxide (DMSO) for analysis. For the CWEs, whole freshwater clam powder was added to boiling water at a $1: 10(\mathrm{w} / \mathrm{w})$ ratio for $20 \mathrm{~min}$, and the mixture was filtered with No. 1 filter paper (Toyo Roshi Kaisha, Tokyo, Japan). The filtrate was lyophilized and then dissolved in phosphate-buffered saline (PBS) for analysis.

Cell Lines and Culture Conditions. Human peripheral blood mononuclear cells (PBMCs) were separated from the fresh blood of healthy donors in Ficoll-Paque PLUS (Amersham Biosciences, Uppsala, Sweden) according to the instructions of the manufacturer. Human acute monocytic leukemia (THP-1) cells were obtained from the Food Industry Research and Development Institute (BCRC, Hsinchu, Taiwan) and were cultured in RPMI1640 medium (Gibco $\mathrm{BRL}$, Gaithersburg, $\mathrm{MD}$ ) supplemented with $0.05 \mathrm{mM} \beta$-mercaptoethanol (Sigma-Aldrich, St. Louis, MO), 2 g/L sodium bicarbonate, $1 \%$ penicillin/streptomycin (PS, Biological Industries, Beithemeek, Israel), and $10 \%$ heat-inactivated fetal bovine serum (FBS) (Gibco $\mathrm{BRL})$ in a humidified atmosphere with $5 \% \mathrm{CO}_{2}$ at $37^{\circ} \mathrm{C}$.

Cytotoxicity of Clam Crude Extracts. THP-1 cells and PBMCs were seeded into 96 -well culture plates at $2 \times 10^{4}$ cells $/ 100 \mu \mathrm{L} /$ well or $2 \times 10^{5}$ cells $/ 100 \mu \mathrm{L} /$ well. A total of $10 \mu \mathrm{L}$ of either CCEs or CWEs at different concentrations were added into each well and incubated for $48 \mathrm{~h}$ in a $\mathrm{CO}_{2}$ incubator at $37^{\circ} \mathrm{C}$. Cell viability was determined using a (3-(4,5-dimethylthiazol-2-yl)-2,5-diphenyltetrazolium bromide (MTT) assay. ${ }^{11}$ The percent relative activity was calculated with the following equation: $\left(A_{1} / A_{0}\right) \times 100 \%$, in which $A_{1}$ is the absorbance of the treated sample and $A_{0}$ is the absorbance of the untreated sample.

Cytokine Measurement. THP-1 cells and PBMCs were seeded into 24 -well culture plates at $1 \times 10^{5}$ cells $/ \mathrm{mL} /$ well or $1 \times 10^{6}$ cells/ $\mathrm{mL} /$ well and incubated at $37^{\circ} \mathrm{C}$ for $24 \mathrm{~h}$. CCEs $(100 \mu \mathrm{g} / \mathrm{mL})$ were then added to the wells. After $24 \mathrm{~h}$ of co-incubation, the supernatants were harvested and assayed using human TNF- $\alpha$ DuoSet, human IL$1 \beta$ DuoSet, and human IL-6 DuoSet enzyme-linked immunosorbent assay (ELISA) kits (R\&D System, Minneapolis, MN).

RNA Isolation and Real-Time Polymerase Chain Reaction (PCR). THP- 1 cells $\left(1 \times 10^{6}\right.$ cells/well $)$ were treated with LPS $(1 \mu \mathrm{g} /$ $\mathrm{mL})$ and CCEs $(100 \mu \mathrm{g} / \mathrm{mL})$ for $3 \mathrm{~h}$. The total THP-1 cellular RNA was then extracted with TRIzol (Invitrogen Life Technologies, Carlsbad, CA) and reverse-transcribed into cDNA using the SuperScript First-Strand Synthesis System (Invitrogen Life Technologies). Human TNF- $\alpha$ and IL-1 $\beta$ mRNA levels were detected using real-time PCR (Applied Biosystems, Carlsbad, CA). The PCR reactions were performed in a $25 \mu \mathrm{L}$ reaction mixture with TNF- $\alpha$,
$\mathrm{IL}-1 \beta$, and $\beta$-actin primers. The primer pairs of TNF- $\alpha, \mathrm{IL}-1 \beta$, and $\beta$ actin were as follows: 5 ' CCC AGG GAC CTC TCT CTA ATC $3^{\prime}$ as the forward primer and 5' ATG GGC TAC AGG CTT GTC ACT 3' as the reverse primer for TNF- $\alpha, 5^{\prime}$ GCA CGA TGC ACC TGT ACG AT $3^{\prime}$ as the forward primer and 5' AGA CAT CAC CAA GCT TTT TTG CT $3^{\prime}$ as the reverse primer for IL- $1 \beta$, and $5^{\prime}$ TTG CCG ACA GGA TGC CAG AA $3^{\prime}$ as the forward primer and 5' GCC GACT CCA CAC GGA GTA CT $3^{\prime}$ as the reverse primer for human $\beta$-actin. Relative quantification of gene expression was performed using $\beta$-actin as a normalization standard. The reaction mixture contained $1 \mu \mathrm{L}$ of cDNA, $0.25 \mu \mathrm{L}$ of forward primer, $0.25 \mu \mathrm{L}$ of reverse primer, $11 \mu \mathrm{L}$ of deuterium depleted water (DDW), and $12.5 \mu \mathrm{L}$ of $2 \mathrm{X}$ realQ PCR master mix (with $10 \mathrm{mM} \mathrm{MgCl}$ and Green DNA dye). Real-time PCR consisted of a $95{ }^{\circ} \mathrm{C}$ denaturation step for $10 \mathrm{~min}$, followed by 40 cycles of $15 \mathrm{~s}$ at $95^{\circ} \mathrm{C}$ and $1 \mathrm{~min}$ at $60{ }^{\circ} \mathrm{C}$.

Western Blot Analysis. THP-1 cells $\left(2 \times 10^{6}\right.$ cells $)$ were either untreated, treated with LPS $(1 \mu \mathrm{g} / \mathrm{mL})$, treated with CCE $(100 \mu \mathrm{g} /$ $\mathrm{mL})$, or treated with a combination of LPS $(1 \mu \mathrm{g} / \mathrm{mL})$ and CCE (100 $\mu \mathrm{g} / \mathrm{mL}$ ) for $24 \mathrm{~h}$. Cells were harvested and mixed with sample buffer (62.5 mM Tris- $\mathrm{HCl}$ at $\mathrm{pH} 6.8,2 \%$ sodium dodecyl sulfate, $5 \% \beta$ mercaptoethanol, $10 \%$ glycerol, and $0.01 \%$ bromophenol blue). After the samples came to a boil, sodium dodecyl sulfate-polyacrylamide gel electrophoresis was performed, and the products were transferred to a polyvinylidene fluoride (PVDF) membrane. The samples were probed with rabbit anti-human nuclear factor- $\kappa \mathrm{B}(\mathrm{NF}-\kappa \mathrm{B})$ polyclonal antibodies (Santa Cruz Biotechnology, Santa Cruz, CA), anti-human I $\kappa \mathrm{B}$ monoclonal antibodies (Epitomics, Inc., Burlingame, $\mathrm{CA}$ ), or antihuman $\beta$-actin polyclonal antibodies (Gene Tex, Inc., San Antonio, TX). After the washes, the membranes were reprobed with goat antirabbit immunoglobulin $G$ and horseradish-peroxidase-conjugated secondary antibodies (Gene Tex). Lastly, the blots were washed, developed, and visualized by enhanced chemiluminescence detection according to the instructions of the manufacturer (Pierce, Appleton, WI).

Endotoxic Shock Model. Balb/c mice (6-8-week-old males) were randomized to receive either $175 \mathrm{mg} / \mathrm{kg}$ of CCEs or a saline/ DMSO (solvent) placebo by intraperitoneal (ip) injection. Immediately afterward, the mice were injected with $15 \mathrm{mg} / \mathrm{kg}$ of LPS ip. After treatment for 2, 6, or $9 \mathrm{~h}$, blood samples were harvested from eye bleeding and centrifuged at $3500 \mathrm{~g}$ for $5 \mathrm{~min}$ to obtain the sera. The murine TNF- $\alpha$, IL- $1 \beta$, and IL- 6 were measured according the instructions included with the ELISA kits (R\&D System, Minneapolis, $\mathrm{MN}$ ). Two independent experiments with four animals each were carried out. The experimental protocols were approved by the Institutional Animal Ethical Committee of the National Chiao Tung University and conducted according to the guidelines by the Committee for the Purpose of Control and Supervision of Experiments on Animals.

Blood Biochemical Analyses. Wistar-Kyoto rats (WKY; 16week-old males) were anesthetized with ether inhalation for approximately $10 \mathrm{~min}$. During the period of anesthesia, one of the femoral arteries was cannulated and connected to a pressure transducer to record arterial pressure (AP) and heart rate on a polygraph recorder (PowerLab, $\mathrm{AD}$ Instruments Co., Mountain View, $\mathrm{CA}$ ). One of the femoral veins was catheterized for the intravenous (iv) administration of $175 \mathrm{mg} / \mathrm{kg}$ of CCE or vitamin K (solvent). The operation was completed within $15 \mathrm{~min}$, and the section wound was smaller than $0.5 \mathrm{~cm}^{2}$. After the operation, the animal was placed in a metabolic cage. The rats awoke soon after the operation. During the experiment, each rat's body temperature was measured rectally using a digital thermometer (HR 1300 thermometer, Yokogawa, Japanese) once every minute. After the administration of $175 \mathrm{mg} / \mathrm{kg}$ of CCE or vitamin $\mathrm{K}$ (solvent) for $48 \mathrm{~h}$, blood samples were collected. ${ }^{12}$ Blood samples for the measurement of white blood cells (Micro OT, Roche Co., Germany) were taken and immediately centrifuged at $3000 \mathrm{~g}$ for $10 \mathrm{~min}$. The plasma samples were diluted 1:100 with distilled water before analysis. Plasma creatinine, alanine aminotransferase (ALT), aspartate aminotransferase (AST), lactic dehydrogenase (LDH), creatine phosphokinase (CPK), creatine phosphokinase-MB (CKMB), and white blood cells (WBCs) were measured with an 
autoanalyzer (Vitros 750, Johnson \& Johnson Co., Rochester, NY) to evaluate various organ functions. Creatinine is a measurement of renal function. ALT and AST are commonly measured in clinical settings as a part of a diagnostic liver function test. $\mathrm{LDH}, \mathrm{CPK}$, and CKMB are a measure of the functioning of the heart as well as other organs (such as muscles). WBC counts are a measure of immune system function.

Tissue Damage. After treatment with CCEs or saline/DMSO for $12 \mathrm{~h}$, the mice were sacrificed. The organs, including heart, lungs, liver, spleen, and kidneys, were removed and fixed in $10 \%$ buffered formalin-saline at $4{ }^{\circ} \mathrm{C}$ overnight and then embedded in paraffin blocks. Tissue sections were prepared and stained with hematoxylin and eosin (H\&E). Tissue morphology was observed under a microscope (Olympus, Center Valley, PA).

Analysis of the CCEs. Gas chromatography analyses were performed with a Hewlett-Packard model 5890 series II or Agilent $6890 \mathrm{~N}$ chromatograph equipped with a DB-5 column $(30 \mathrm{~m} \times 0.25$ $\mathrm{mm}$ inner diameter; $0.25 \mu \mathrm{m}$ film; oven gradient at $50{ }^{\circ} \mathrm{C}$ for $2 \mathrm{~min}$, then $15{ }^{\circ} \mathrm{C} / \mathrm{min}$ until the temperature reached $300^{\circ} \mathrm{C}$, and held at 300 ${ }^{\circ} \mathrm{C}$ for $5 \mathrm{~min} ; 300{ }^{\circ} \mathrm{C}$ injector; $250{ }^{\circ} \mathrm{C}$ interface; and 1:40 split ratio using helium carrier gas at a 13 psi column head pressure). Gas chromatography-mass spectrometry (GC-MS) was performed on a Hewlett-Packard 5890 II GC (J\&W DB-5MS column, $30 \mathrm{~m} \times 0.25$ mm inner diameter; $0.25 \mu \mathrm{m}$ film; $280{ }^{\circ} \mathrm{C}$ oven; $270{ }^{\circ} \mathrm{C}$ injector; and $280{ }^{\circ} \mathrm{C}$ GC-MS transfer line) coupled to a TRIO-2000 micromass spectrometer (Micromass, Beverly, MA).

Statistical Analysis. All data are expressed as the mean \pm standard deviation (SD). Statistical analyses were performed with Graph Pad Prism (version 5). Statistical evaluation of the data was carried out by unpaired Student's $t$ test for comparison between two groups and oneway analysis of variation (ANOVA) followed by Dunnett's test for comparisons across more than two groups. Statistical significance was set at $p<0.05$.

\section{RESULTS}

Effects of $C$. fluminea Extracts on Inductions of TNF- $\alpha$, IL-1 $\boldsymbol{\beta}$, or IL-6 in Vitro. To determine whether the active substances in $C$. fluminea decrease inflammation, the dry clam powders were added to chloroform or hot water to obtain CCEs and CWEs. The yields of CCEs and CWEs were approximately 8.2 and $30.5 \%$, respectively (Table 1 ). Neither of

Table 1. Yield of Extracts Isolated from Residual Meat of $C$. fluminea

\begin{tabular}{lr}
\multicolumn{1}{c}{ solvent } & \multicolumn{1}{c}{ yield $^{a, b}(\%)$} \\
chloroform (CCE) & $8.19 \pm 0.28$ \\
chloroform (CCE) residual & $91.88 \pm 0.35$ \\
hot water (CWE) & $30.45 \pm 0.97$ \\
hot water (CWE) residual & $75.93 \pm 8.71$
\end{tabular}

${ }^{a}$ Dry weight of solvent extract $(\mathrm{g}) /$ dry weight of clam powder $(\mathrm{g})$. ${ }^{b}$ Mean of three replications \pm standard deviation.

the extracts affected the expression of inflammatory cytokines (TNF- $\alpha$, IL-1 $\beta$, or IL-6) independently (data not shown). CCEs in doses $\leq 250 \mu \mathrm{g} / \mathrm{mL}$ and CWEs in doses $\leq 500 \mu \mathrm{g} / \mathrm{mL}$ did not affect the viability of the cells (data not shown). Furthermore, LPS $(1 \mu \mathrm{g} / \mathrm{mL})$ is used as a stimulator for inflammation and can trigger the expression of cytokines, such as TNF- $\alpha$, IL- $1 \beta$, or IL- 6 , in monocyte-like THP- 1 cells or PBMCs. On the basis of these abilities, the effects of CCEs or CWEs on the production of pro-inflammatory cytokines were examined. Figure $1 \mathrm{~A}$ shows that the CCEs significantly reduced the expression of TNF- $\alpha$, IL- $1 \beta$, and IL- 6 released by LPSstimulated THP-1 cells. Unlike the CCEs, the CWEs enhanced the release of LPS-induced TNF- $\alpha$ in THP-1 cells (Figure 1B). Similar results were obtained in human PBMCs (panels A and

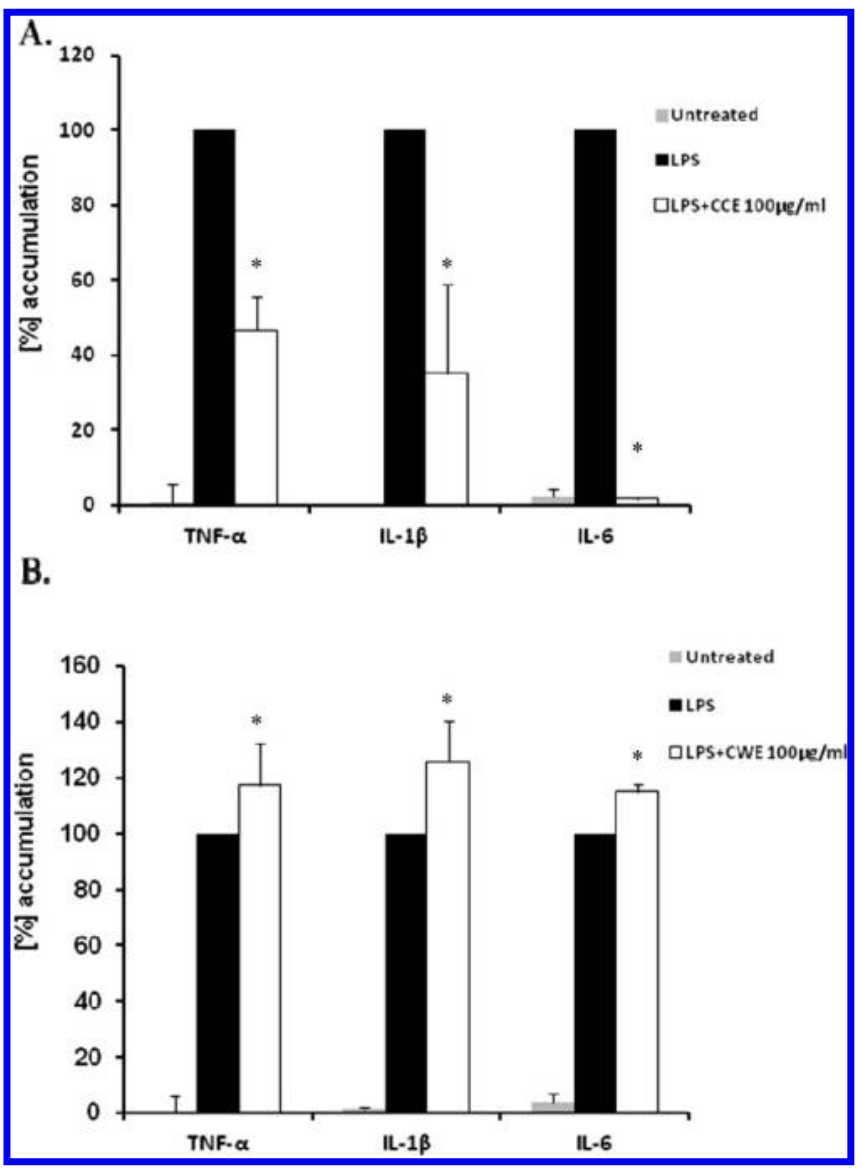

Figure 1. Effects of clam extracts on the production of proinflammatory cytokines in THP-1 cells. THP-1 cells stimulated by LPS were treated with (A) CCEs or (B) CWEs. The amounts of TNF$\alpha, \mathrm{IL}-1 \beta$, and IL- 6 in the supernatants were measured and expressed as a percentage of the respective cytokine concentration accumulated in the supernatant of LPS-activated THP-1 cells (100\%). The data are expressed as the mean \pm standard error $(\mathrm{SE})$ of three determinations. (*) $p<0.05$ versus LPS alone.

$\mathrm{B}$ of Figure 2). These results indicate that CCEs can lower the releases of pro-inflammatory cytokines but that CWEs slightly increase the release of pro-inflammatory cytokines under LPS stimulation.

CCEs Decrease TNF- $\alpha$ and IL- $1 \beta$ Production in Vivo. This study reveals that CCEs inhibit the release of proinflammatory cytokines induced by LPS in vitro but CWEs do not. Next, a well-established endotoxic shock model was used to further examine the effects of CCEs on pro-inflammatory cytokine production in vivo. TNF- $\alpha$ was undetectable in the sera of the untreated or CCE-treated mice (Figure 3A). Cotreatment with CCEs significantly reduced endotoxin-induced TNF- $\alpha$ release (Figure 3A) and IL- $1 \beta$ production $2 \mathrm{~h}$ after LPS treatment when compared to the LPS-treated, untreated, or CCE-treated mice (Figure 3B).

In addition to inducing inflammation, LPS is also a potent cytotoxin. As the results show, mice in the LPS-treated group experienced bleeding in the liver, heart, spleen, lung, and kidney (Figure 4). However, treatment with CCEs dramatically reduced LPS-induced damage (Figure 4). Furthermore, the effects of CCEs on otherwise healthy organs were also examined to determine the safety of CCEs. Table 2 shows that CCE treatment did not cause changes in creatinine, AST, $\mathrm{ALT}$, or WBCs, and it lowered the amounts of $\mathrm{LDH}, \mathrm{CKMB}$, 


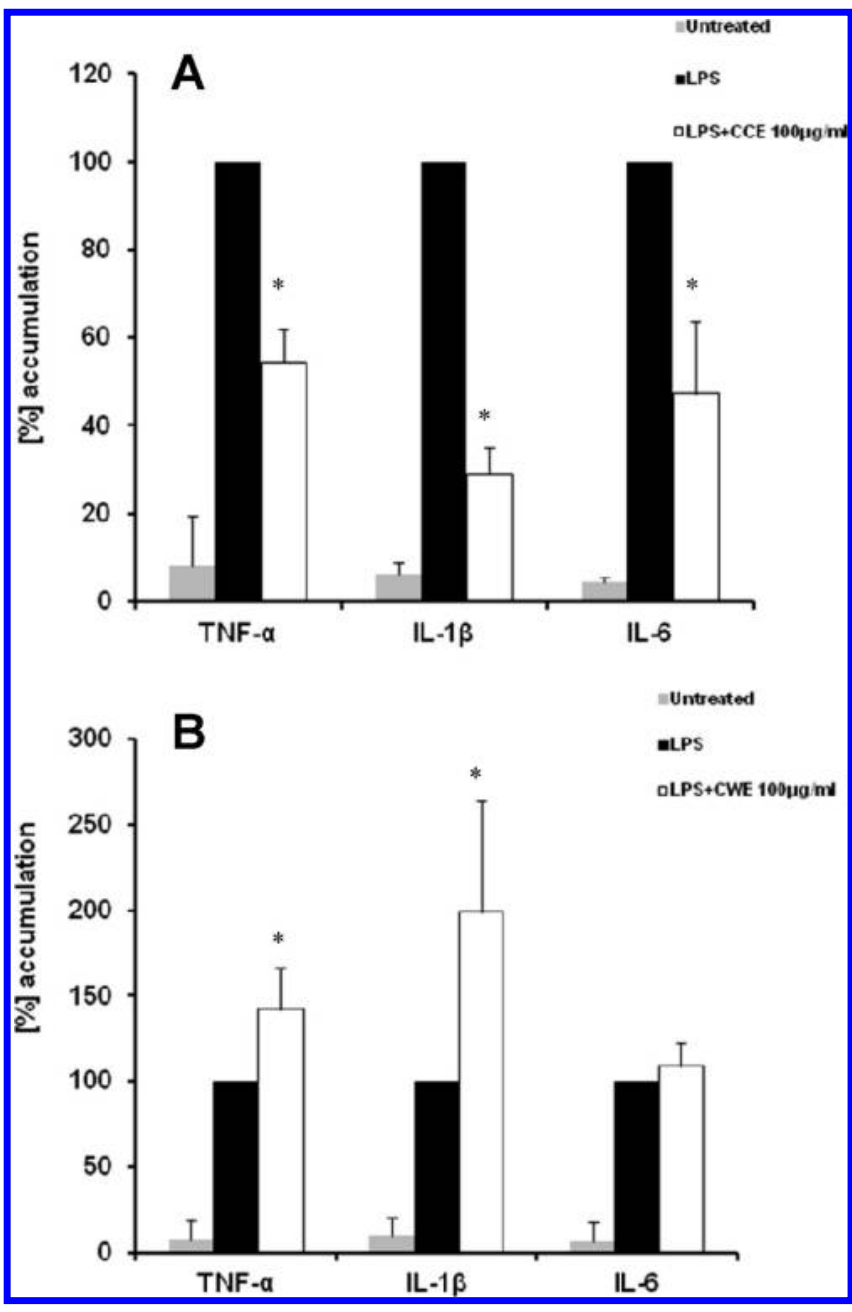

Figure 2. Effects of clam extracts on the production of proinflammatory cytokines in PBMCs. PBMCs stimulated by LPS were treated with (A) CCEs or (B) CWEs. The amounts of TNF- $\alpha$, IL- $1 \beta$, and IL- 6 in the supernatants were measured by ELISA. The data are expressed as a percentage of the respective cytokine concentration accumulated in the supernatant of LPS-activated PBMC cells (100\%). The data are presented as the mean \pm SE of three determinations. $(*)$ $p<0.05$ versus LPS alone.

and CPK in the sera when compared to the group treated with solvent (vitamin $\mathrm{K}$ ). On the basis of these results, CCE treatment did not cause cellular damage in the kidneys, liver, heart, or muscles (Table 2). CCEs not only inhibit the concentration of pro-inflammatory cytokines but also decrease organ damage caused by LPS. Furthermore, they are safe for animals.

Effects of CCEs on the Gene Expression of TNF- $\alpha$ and IL-1 $\beta$ after LPS Stimulation. The mechanism by which CCEs inhibit the release of pro-inflammatory cytokines was examined. First, we determined whether the CCEs could influence the mRNA levels of pro-inflammatory cytokines. LPS stimulation leads to a 14.9-fold increase in TNF- $\alpha$ mRNA expression and a 3.97 -fold increase in IL- $1 \beta$ gene expression in THP-1 cells when compared to untreated cells (Figure 5A). However, after co-incubation with CCEs $(100 \mu \mathrm{g} / \mathrm{mL})$, the levels of TNF- $\alpha$ mRNA expression induced by LPS were decreased to only 8fold higher than baseline in THP-1 cells $(p=0.013)$. Similarly, the increase in the level of IL- $1 \beta$ mRNA expression was

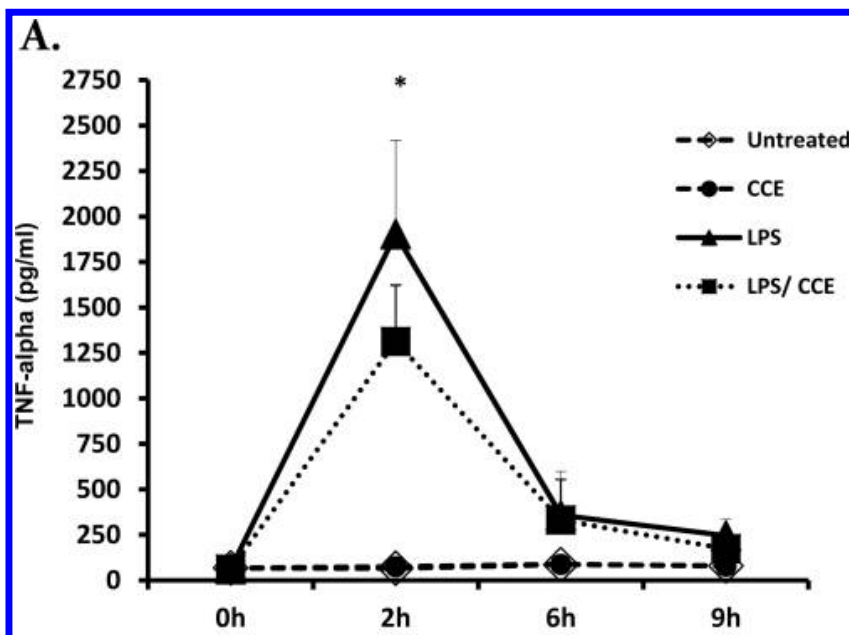

B.

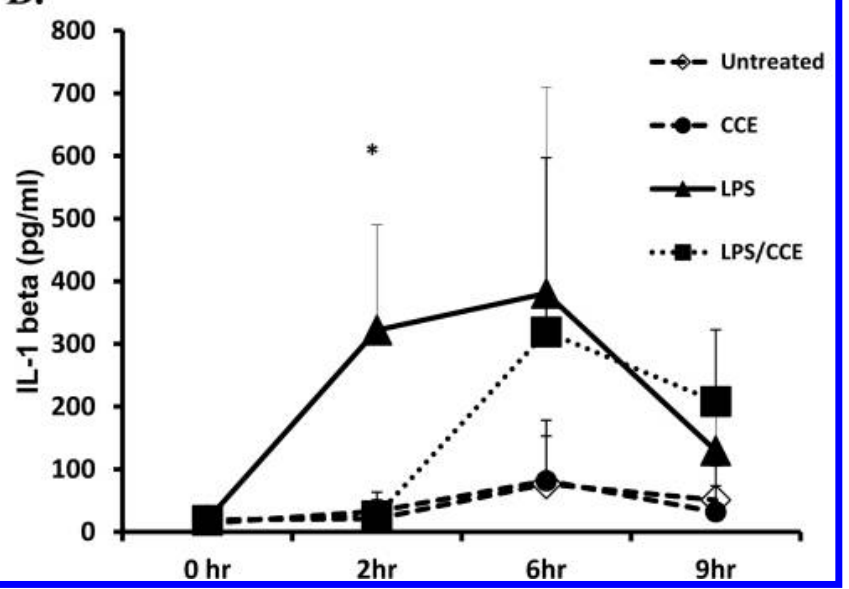

Figure 3. CCEs decreased the production of TNF- $\alpha$ and IL- $1 \beta$ in vivo. Male Balb/c mice received CCEs or saline/DMSO by ip injection immediately after injection with LPS. Serum samples were collected at different times, and the levels of murine TNF- $\alpha$ and $\mathrm{IL}-1 \beta$ were determined by ELISA as described in the Materials and Methods. Two independent experiments with four animals each were carried out. $(*)$ $p<0.05$; LPS/CCE group versus LPS group.

lowered to 2.9-fold higher than the baseline in THP-1 cells ( $p=$ 0.048) (Figure 5A).

The above results reveal that CCEs preferentially act on the expression of the TNF- $\alpha$ gene. Thus, we investigated whether CCEs influence the pathway of NF- $\kappa \mathrm{B}$ activation, which is a major pathway that regulates the expression of TNF- $\alpha$. Figure $5 \mathrm{~B}$ shows that $\mathrm{CCEs}$ can dramatically enhance $\mathrm{I} \kappa \mathrm{B}-\alpha$ expression and decrease the induction of the $\mathrm{pI} \kappa \mathrm{B}-\alpha$ protein in THP- 1 cells. Additionally, the data show that combined treatment with LPS and CCEs caused lesser formation of the $\mathrm{pI} \kappa \mathrm{B}-\alpha$ protein than treatment with LPS alone, which resulted in increased $\mathrm{I} \kappa \mathrm{B}$ $\alpha$ proteins. The $\mathrm{I} \kappa \mathrm{B}$ protein can retain NF- $\kappa \mathrm{B}$ in the cytoplasm and suppress nuclear translocation of NF- $\kappa \mathrm{B}$. Therefore, the gene expression of NF- $\kappa \mathrm{B}$-activated pro-inflammatory cytokines, such as TNF- $\alpha$, are decreased by CCEs in the presence of LPS. Taken together, CCEs may inhibit NF- $\kappa$ B-mediated gene transcription in cells by preventing phosphorylation and enhancing $\mathrm{I} \kappa \mathrm{B}-\alpha$ expression.

Analysis of CCEs. GC-MS was used to determine which CCEs have anti-inflammatory activities. The major components were as follows (in descending order by concentration; also, see Table 3): (1) cholesterol (23.24 mg/100 mg of CCE), (2) n- 


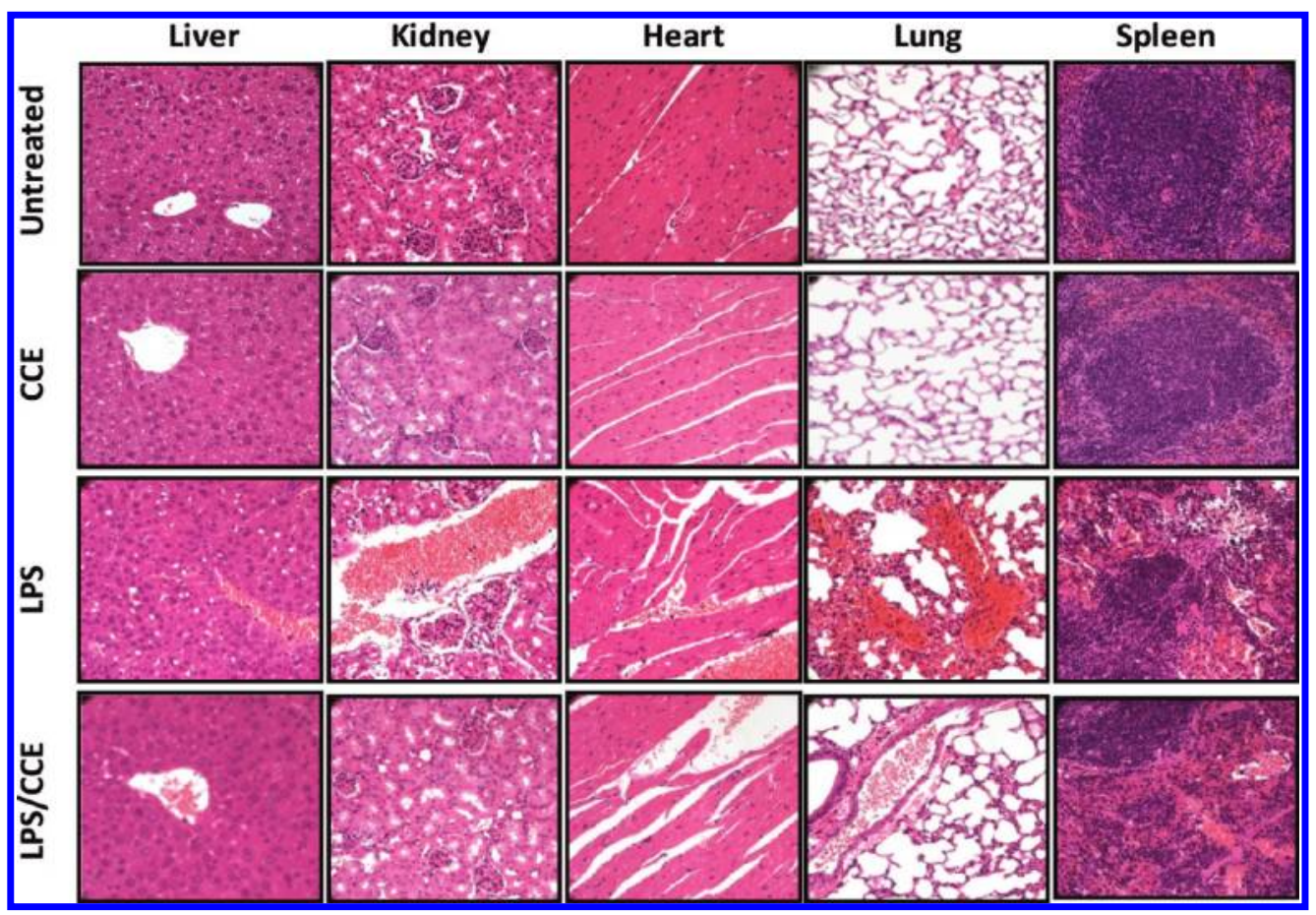

Figure 4. Histopathological features of the liver, kidney, heart, lung, and spleen of different treatment groups. Portions of the organs were fixed in 4\% paraformaldehyde overnight, embedded in paraffin, and cut into slices. Organ sections were stained with $\mathrm{H} \& \mathrm{E}$ (original magnification $=400 \times$ ).

Table 2. Effect of CCEs on Blood Biomarkers Reflecting Tissue Damage

\begin{tabular}{llcc} 
& & \multicolumn{2}{c}{ levels } \\
\cline { 3 - 4 } biochemical factors & \multicolumn{1}{c}{ organs } & untreated & CCE \\
creatinine $(\mathrm{mg} / \mathrm{dL})$ & kidney & $0.2 \pm 0.1^{a}$ & $0.3 \pm 0.1$ \\
AST (units/L) & liver & $603 \pm 396.4$ & $711.5 \pm 476.2$ \\
ALT (units/L) & liver & $89.1 \pm 38.8$ & $76.9 \pm 36.4$ \\
LDH (units/L) & heart & $530.5 \pm 70.2$ & $392.4 \pm 132.8^{b}$ \\
CPK (units/L) & heart & $427.5 \pm 14.4$ & $235.3 \pm 101.2^{b}$ \\
CKMB (ng/mL) & heart & $499.3 \pm 73.4$ & $324.5 \pm 115.0^{b}$ \\
WBC & immune & $5.2 \pm 1.4$ & $5.5 \pm 2.1$
\end{tabular}

${ }^{a}$ Mean of three replications \pm standard deviation. ${ }^{b} p<0.05$ versus untreated group.

hexadecanoic acid (9.48 mg/100 mg of CCE), (3) campesterol (7.335 mg/100 mg of CCE), (4) oleic acid $(6.665 \mathrm{mg} / 100 \mathrm{mg}$ of CCE), (5) ergosta-5,22-dien-3-ol $(6.36 \mathrm{mg} / 100 \mathrm{mg}$ of CCE), (6) stigmasterol (3.75 mg/100 mg of CCE), (7) octadecanic acid (3.72 mg/100 $\mathrm{mg}$ of CCE), and (8) 11eicosenoic acid methylester $(3.59 \mathrm{mg} / 100 \mathrm{mg}$ of CCE $)$. On the basis of their structures, the components can be divided into sterols $(1,3,5$, and 6$)$ and fatty acids $(2,4,7$, and 8$)$.

\section{DISCUSSION}

As previously described, C. fluminea is used not only as a food but also as a remedy for liver diseases in Taiwan. Although many bioactivities, such as hepatoprotection, ${ }^{5,6}$ antihypertension, ${ }^{7}$ antitumorigenesis, ${ }^{8}$ and hypocholesterolemia, ${ }^{9}$ had been reported, it remained unclear whether $C$. fluminea has an effect on inflammation. In this study, we evaluated the effects of $C$. fluminea crude extracts on inflammatory processes, and the results clearly indicate that CCEs have the ability to suppress the LPS-induced release of pro-inflammatory cytokines; CCEs were especially effective against TNF- $\alpha$ by increasing $\mathrm{I} \kappa \mathrm{B}$ protein expression. We also analyzed the substances in CWEs by GC-MS (data not shown). Uric acid (UA), one of substances in CWEs, is already known to promote inflammation. ${ }^{13,14}$ Thus, CWEs slightly increase the release of proinflammatory cytokines under LPS stimulation.

TNF- $\alpha$ is a mediator of many pathologies, including rheumatoid arthritis (RA), endotoxic shock, systemic lupus erythematosus, $^{15}$ tumorigenesis, and systemic inflammatory response. TNF- $\alpha$ is thought to exert multiple biological effects on endothelial cells during the inflammatory process, such as the induction of leukocyte adhesion molecules ${ }^{16}$ and the release of pro-inflammatory cytokines. ${ }^{17,18}$ Anti-TNF- $\alpha$ use has been associated with a $51 \%$ reduction in the risk of developing diabetes in patients with RA. ${ }^{19}$ In addition, anti-TNF- $\alpha$ treatments have been approved by regulatory authorities in the United States and Europe to treat RA, and they represent a significant new addition to the available therapeutic options. ${ }^{20}$

For the first time, our data demonstrate the antiinflammatory effects of CCEs, which may play an important role as a traditional remedy. Two mechanisms may be involved in this process. First, CCEs enhance $\mathrm{I} \kappa \mathrm{B}-\alpha$ and decrease $\mathrm{pI} \kappa \mathrm{B}-\alpha$ protein expression in THP-1 cells (Figure 5B), which inactivates the NF- $\kappa \mathrm{B}$ molecule. NF- $\kappa \mathrm{B}$ is an important transcriptional factor for activating the expression of the TNF- $\alpha$ gene. Thus, CCEs could reduce the mRNA expression of TNF- $\alpha$ (Figure 5A) and also markedly attenuate production of this cytokine. Second, because the production of TNF- $\alpha$ is known to be responsible for the induction of other proinflammatory mediators, such as IL- $1 \beta$ and IL- $6,{ }^{21,22}$ CCEs also lower expression of these mediators. Our results also show the downregulation of the pro-inflammatory cytokines IL- $1 \beta$ and IL- 6 by CCEs in THP-1 and PBMC cells treated with LPS; this effect may be associated with the reduction of TNF- $\alpha$ release (Figures 1A and 2A). Moreover, a well-described mouse model $^{23}$ was also used to examine the anti-inflammatory effects of CCEs. The data show that CCEs significantly reduced not 


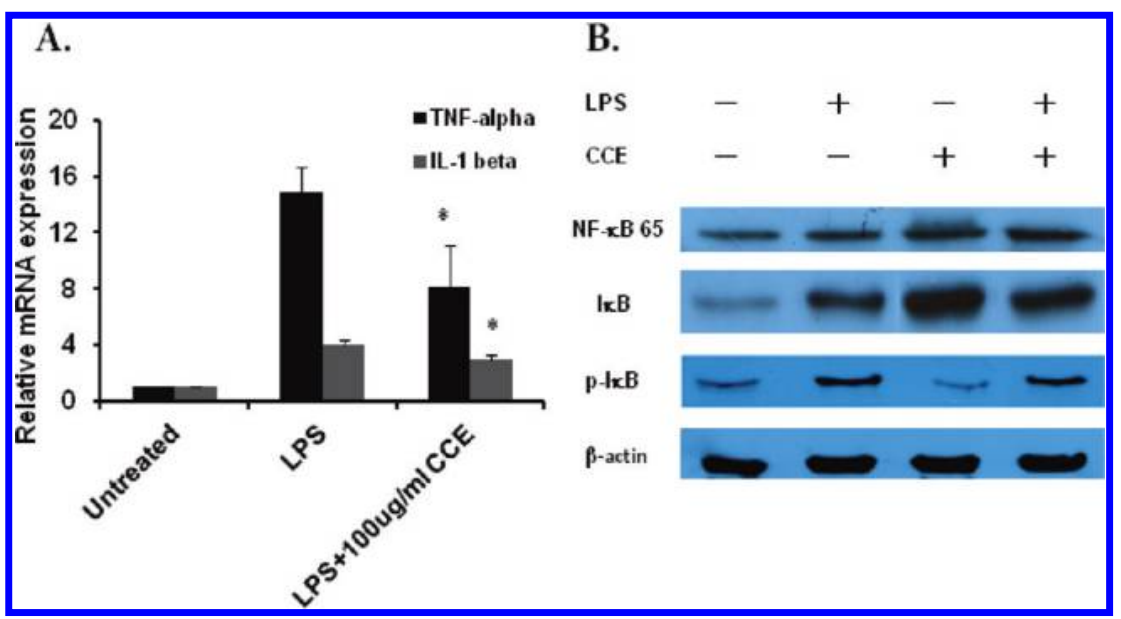

Figure 5. Mechanism by which CCEs attenuate LPS-induced inflammation. (A) Real-time PCR analysis of the mRNA expression of TNF- $\alpha$ and IL$1 \beta$ in THP- 1 cells. The relative expressions of TNF- $\alpha$ and IL- $1 \beta$ are shown as percentages of $\beta$-actin. The data are expressed as the mean \pm SE of three determinations. $(*) p<0.05$; CCE treatment versus LPS alone. (B) Effects of CCEs on the expression of NF- $\kappa \mathrm{B}$ (p65), I $\kappa \mathrm{B}-\alpha$, and pI $\kappa \mathrm{B}-\alpha$ in LPS-stimulated THP-1 cells. These experiments were repeated 3 times, and representative results are shown.

Table 3. Components of CCEs by GC-MS Analysis

\begin{tabular}{lc}
\multicolumn{1}{c}{ components } & $(\mathrm{mg} / 100 \mathrm{mg}$ of CCE $)$ \\
cholesterol & $23.24 \pm 0.14^{a}$ \\
$n$-hexadecanoic acid (palmitic acid) & $9.48 \pm 0.08$ \\
campesterol & $7.34 \pm 0.27$ \\
ergosta-5,22-dien-3-ol (brassicasterol) & $6.36 \pm 0.16$ \\
oleic acid & $4.24 \pm 0.324$ \\
stigmasterol & $3.73 \pm 0.04$ \\
octadecanoic acid (stearic acid) & $3.72 \pm 0.05$ \\
11-eicosenoic acid methylester & $3.59 \pm 0.18$ \\
${ }^{a}$ Mean of three replications \pm standard deviation.
\end{tabular}

only the production of TNF- $\alpha$ but also IL-1 $\beta$ (Figure 3 ). Thus, CCEs may be developed as a good therapeutic option for certain diseases in which TNF- $\alpha$ is a pathogenic mediator.

We subsequently used GC-MS to analyze the components of the C. fluminea chloroform extract. On the basis of the results (see Supplementary Figure 1 of the Supporting Information), we found that the eight major components of the CCE are cholesterol (23.24\%), palmitic acid (9.48\%), campesterol (7.34\%), brassicasterol (6.36\%), oleic acid (4.24\%), stigmasterol $(3.73 \%)$, stearic acid (3.72\%), and 11-eicosenoic acid methylester (3.59\%) (Table 3). These components can be divided into phytosterols and fatty acids. The phytosterols stigmasterol, campesterol, and brassicasterol may reduce the infiltration of TPA-induced neutrophils into inflamed tissue. ${ }^{24}$ Stigmasterol is also an anti-inflammatory agent used in the treatment of rheumatic diseases, and it can inhibit the release of MMP-3 and MMP-13 from chondrocytes after IL-1 $\beta$ stimulation by suppressing $\mathrm{I} \kappa \mathrm{B}$ degradation. ${ }^{25,26}$ The fatty acids in the CCEs, such as oleic acid, may reduce LPS-induced VCAM-1 mRNA levels and inhibit $\mathrm{NF} \kappa \mathrm{B}$ activation in endothelial cells, and they may also inhibit the LPS-induced production of $\mathrm{NO}$ and $\mathrm{PGE}_{2}$ by suppressing the expression of iNOS and COX-2 in murine microglial cells. ${ }^{27,28}$ Stearic acid may attenuate bile duct ligation-induced leukocyte infiltration and NF- $\kappa$ B activation in Sprague Dawley (SD) rats, ${ }^{29}$ and palmitic acid may inhibit the LPS-induced production of TNF$\alpha$, IL- $1 \beta$, and IL-6 in J774A.1 murine macrophages. ${ }^{30}$
In summary, CCEs inhibit pro-inflammatory cytokines, especially TNF- $\alpha$, and they may be used as a cost-effective, natural treatment for inflammatory diseases.

\section{ASSOCIATED CONTENT}

\section{S Supporting Information}

Total ion chromatograms obtained by GC-MS analysis on CCEs: (1) cholesterol, (2) palmitic acid, (3) campesterol, (4) brassicasterol, (5) oleic acid, (6) stigmasterol, (7) stearic acid, and (8) 11-eicosenoic acid methylester (Supplementary Figure $1)$. This material is available free of charge via the Internet at http://pubs.acs.org.

\section{AUTHOR INFORMATION}

\section{Corresponding Author}

*Telephone: 886-3-5712121, ext. 56955. Fax: 886-3-5729288. E-mail: fish@mail.tcu.edu.tw (R.-P.L.); liaonms@pchome.com. tw (K.-W.L.).

\section{Author Contributions}

${ }^{\dagger}$ These authors contributed equally to this work.

\section{Author Contributions}

${ }^{\perp}$ These authors contributed equally to this work.

\section{Funding}

This work was supported in part by the UST-UCSD International Center of Excellence in Advanced Bioengineering sponsored by the Taiwan National Science Council I-RiCE Program under Grant NSC-100-2911-I-009-101.

\section{Notes}

The authors declare no competing financial interest.

\section{ACKNOWLEDGMENTS}

We are grateful to Mike Biological Technologies Company for material and technical support.

\section{ABBREVIATIONS USED}

PBMC, peripheral blood mononuclear cell; THP-1, human acute monocytic leukemia; TNF- $\alpha$, tumor necrosis factor- $\alpha$; IL6 , interleukin-6; IL-1 $\beta$, interleukin-1 $\beta$; LPS, lipopolysaccharide 


\section{REFERENCES}

(1) Medzhitov, R. Origin and physiological roles of inflammation. Nature 2008, 454, 428-435.

(2) Paul, A. T.; Gohil, V. M.; Bhutani, K. K. Modulating TNF- $\alpha$ signaling with natural products. Drug Discovery Today 2006, 11, 725732.

(3) Mills, K. H.; Dunne, A. Immune modulation: IL-1, master mediator or initiator of inflammation. Nat. Med. 2009, 15, 1363-1364.

(4) Kaplanski, G.; Marin, V.; Montero-Julian, F.; Mantovani, A.; Farnarier, C. IL-6: A regulator of the transition from neutrophil to monocyte recruitment during inflammation. Trends Immunol. 2003, 24, 25-29.

(5) Chen, C.; Lin, C. Hepatoprotective effects of clam extract supplementation on subacute hepatitis induced by carbon tetrachloride in rats. Taiwanese J. Agric. Chem. Food Sci. 2003, 41, 159-166.

(6) Lin, C. Effects of freshwater clam extract on liver functions in alcoholic liver injury. Nutr. Sci. J. 2003, 28, 26-33.

(7) Tsai, J. S.; Lin, T. C.; Chen, L. C.; Pan, B. S. The inhibitory of freshwater clam (Corbicula fluminea, Muller) muscle protein hydrolysates on angiotensin I converting enzyme. Process Biochem. 2006, 41, 2276-2281.

(8) Huang, Y. T.; Huang, Y. H.; Hour, T. C.; Pan, B. S.; Liu, Y. C.; Pan, M. H. Apoptosis-inducing active components from Corbicula fluminea through activation of caspase- 2 and production of reactive oxygen species in human leukemia HL-60 cells. Food Chem. Toxicol. 2006, 44, 1261-1272.

(9) Chijimatsu, T.; Tatsuguchi, I.; Oda, H.; Mochizuki, S. A freshwater clam (Corbicula fluminea) extract reduces cholesterol level and hepatic lipids in normal rats and xenobiotics-induced hypercholesterolemic rats. J. Agric. Food Chem. 2009, 57, 3108-3112.

(10) Lee, R. P.; Subeq, Y. M.; Lee, C. J.; Hsu, B. G.; Peng, T. C. Freshwater clam extract decreased hemorrhagic shock-induced liver injury by attenuating TNF- $\alpha$ production. Biol. Res. Nurs. 2011, DOI: $10.1177 / 1099800411408881$.

(11) Mosmann, T. Rapid colorimetric assay for cellular growth and survival: Application to proliferation and cytotoxicity assays. J. Immunol. Methods 1983, 65, 55-63.

(12) Peng, T. C.; Subeq, Y. M.; Lee, C. J.; Lee, C. C.; Tsai, C. J.; Chang, F. M.; Lee, R. P. Freshwater clam extract ameliorates acute liver injury induced by hemorrhage in rats. Am. J. Chin. Med. 2008, 36, $1121-1133$.

(13) Lyngdoh, T.; Marques-Vidal, P.; Paccaud, F.; Preisig, M.; Waeber, G.; Bochud, M.; Vollenweider, P. Elevated serum uric acid is associated with high circulating inflammatory cytokines in the population-based Colaus study. PLoS One 2011, DOI: 10.1371/ journal.pone.0019901.

(14) Gasse, P.; Riteau, N.; Charron, S.; Girre, S.; Fick, L.; Petrilli, V.; Tschopp, J.; Lagente, V.; Quesniaux, V. F.; Ryffel, B.; Couillin, I. Uric acid is a danger signal activating NALP3 inflammasome in lung injury inflammation and fibrosis. Am. J. Respir. Crit. Care Med. 2009, 179, 903-913.

(15) Postal, M.; Appenzeller, S. The role of tumor necrosis factor- $\alpha$ (TNF- $\alpha$ ) in the pathogenesis of systemic lupus erythematosus. Cytokine 2011, 56, 537-543.

(16) Pober, J. S.; Lapierre, L. A.; Stolpen, A. H.; Brock, T. A.; Springer, T. A.; Fiers, W.; Bevilacqua, M. P.; Mendrick, D. L.; Gimbrone, M. A., Jr. Activation of cultured human endothelial cells by recombinant lymphotoxin: Comparison with tumor necrosis factor and interleukin 1 species. J. Immunol. 1987, 138, 3319-3324.

(17) Jirik, F. R.; Podor, T. J.; Hirano, T.; Kishimoto, T.; Loskutoff, D. J.; Carson, D. A.; Lotz, M. Bacterial lipopolysaccharide and inflammatory mediators augment IL-6 secretion by human endothelial cells. J. Immunol. 1989, 142, 144-147.

(18) Desch, C. E.; Dobrina, A.; Aggarwal, B. B.; Harlan, J. M. Tumor necrosis factor- $\alpha$ exhibits greater proinflammatory activity than lymphotoxin in vitro. Blood 1990, 75, 2030-2034.

(19) Antohe, J. L.; Bili, A.; Sartorius, J. A.; Lester Kirchner, H.; Morris, S. J.; Dancea, S.; Wasko, M. C. Diabetes risk in rheumatoid arthritis: Reduced incidence with anti-tumor necrosis factor- $\alpha$ therapy. Arthritis Care Res. 2012, 64, 215-221.

(20) Feldmann, M.; Maini, R. N. Anti-TNF- $\alpha$ therapy of rheumatoid arthritis: What have we learned? Annu. Rev. Immunol. 2001, 19, 163196.

(21) Dinarello, C. A. Proinflammatory cytokines. Chest 2000, 118, 503-508.

(22) Jansky, L.; Reymanova, P.; Kopecky, J. Dynamics of cytokine production in human peripheral blood mononuclear cells stimulated by LPS or infected by Borrelia. Physiol. Res. 2003, 52, 593-598.

(23) Kiemer, A. K.; Hartung, T.; Huber, C.; Vollmar, A. M. Phyllanthus amarus has anti-inflammatory potential by inhibition of iNOS, COX-2, and cytokines via the NF- $\kappa$ B pathway. J. Hepatol. 2003, $38,289-297$.

(24) Navarro, A.; De las Heras, B.; Villar, A. Anti-inflammatory and immunomodulating properties of a sterol fraction from Sideritis foetens Clem. Biol. Pharm. Bull. 2001, 24, 470-473.

(25) Gabay, O.; Sanchez, C.; Salvat, C.; Chevy, F.; Breton, M.; Nourissat, G.; Wolf, C.; Jacques, C.; Berenbaum, F. Stigmasterol: A phytosterol with potential anti-osteoarthritic properties. Osteoarthritis Cartilage 2010, 18, 106-116.

(26) Garcia, M. D.; Saenz, M. T.; Gomez, M. A.; Fernandez, M. A. Topical antiinflammatory activity of phytosterols isolated from Eryngium foetidum on chronic and acute inflammation models. Phytother. Res. 1999, 13, 78-80.

(27) Oh, Y. T.; Lee, J. Y.; Lee, J.; Kim, H.; Yoon, K. S.; Choe, W.; Kang, I. Oleic acid reduces lipopolysaccharide-induced expression of iNOS and COX-2 in BV2 murine microglial cells: Possible involvement of reactive oxygen species, p38 MAPK, and IKK/NF$\kappa \mathrm{B}$ signaling pathways. Neurosci. Lett. 2009, 464, 93-97.

(28) Carluccio, M. A.; Massaro, M.; Bonfrate, C.; Siculella, L.; Maffia, M.; Nicolardi, G.; Distante, A.; Storelli, C.; De Caterina, R. Oleic acid inhibits endothelial activation: A direct vascular antiatherogenic mechanism of a nutritional component in the mediterranean diet. Arterioscler., Thromb., Vasc. Biol. 1999, 19, 220-228.

(29) Pan, P. H.; Lin, S. Y.; Ou, Y. C.; Chen, W. Y.; Chuang, Y. H.; Yen, Y. J.; Liao, S. L.; Raung, S. L.; Chen, C. J. Stearic acid attenuates cholestasis-induced liver injury. Biochem. Biophys. Res. Commun. 2010, 391, 1537-1542.

(30) Hua, K. F.; Hsu, H. Y.; Su, Y. C.; Lin, I. F.; Yang, S. S.; Chen, Y. M.; Chao, L. K. Study on the antiinflammatory activity of methanol extract from seagrass Zostera japonica. J. Agric. Food Chem. 2006, 54, $306-311$. 